\title{
man \\ Reliability of the Hip Extension Lower Exercise as a Measure of Eccentric Hamstring Strength
}

\author{
Joey O'Brien ${ }^{1,2, *}$, Declan Browne ${ }^{1}$, Des Earls ${ }^{1}$ and Clare Lodge ${ }^{1}$ \\ 1 HealthCore, Department of Science and Health, Institute of Technology Carlow, R93 V960 Carlow, Ireland; \\ Declanbrowne@itcarlow.ie (D.B.); desearls@itcarlow.ie (D.E.); clairelodge@itcarlow.ie (C.L.) \\ 2 High Performance Unit, WIT Arena, X91 P20H Waterford, Ireland \\ * Correspondence: C00232530@itcarlow.ie; Tel.: +353-863-101-163
}

check for updates

Citation: O'Brien, J.; Browne, D.; Earls, D.; Lodge, C. Reliability of the Hip Extension Lower Exercise as a Measure of Eccentric Hamstring Strength. Biomechanics 2022, 2, 1-6. https://doi.org/10.3390/

biomechanics2010001

Academic Editor: Justin Keogh

Received: 9 October 2021

Accepted: 24 December 2021

Published: 30 December 2021

Publisher's Note: MDPI stays neutral with regard to jurisdictional claims in published maps and institutional affiliations.

Copyright: (C) 2021 by the authors. Licensee MDPI, Basel, Switzerland. This article is an open access article distributed under the terms and conditions of the Creative Commons Attribution (CC BY) license (https:// creativecommons.org/licenses/by/ $4.0 /)$.

\begin{abstract}
Hamstring strain injury (HSI) is a very common lower-body injury in field sports, and eccentric (ECC) hamstring strength is a potential modifiable risk factor, therefore having reliable eccentric hamstring strength assessments is critical. The aim of this study was to access test-retest reliability of the hip extension lower (HEL) exercise as a measure of ECC hamstring strength and interlimb asymmetries. Twelve male elite level soccer players (mean; age: 21.8 years; height: $180.4 \mathrm{~cm}$; weight: $75.7 \mathrm{~kg}$ ) volunteered to participate in this study. Participants were from the same soccer club, covered all playing positions, and had no current injury issues. Participants performed two familiarization sessions to acquaint themselves with the device and exercise protocol. During testing, each participant performed three repetitions with 60s intra-set recovery provided. Average and peak force $(\mathrm{N})$ was recorded for both limbs. Testing sessions took place on the same day and time over a two-week pre-season period and followed a full recovery day. Intraclass Correlation Coefficient (ICC), Coefficient of Variation (CV\%), Minimal Detectable Change (MDC) and Typical Error (TE) were used to assess reliability. The HEL showed excellent reliability for average force $(\mathrm{N})$ in the left $(\mathrm{ICC}(95 \% \mathrm{CI})=0.9(0.7-0.97) ; \mathrm{TE}=14.1 \mathrm{~N}, \mathrm{CV} \%=1.87 ; \mathrm{MDC}=39.06 \mathrm{~N})$ and right $(\mathrm{ICC}(95 \% \mathrm{CI})=$ $0.91(0.73-0.97) ; \mathrm{TE}=20.89 \mathrm{~N}, \mathrm{CV} \%=3.26 ; \mathrm{MDC}=57.87 \mathrm{~N})$ limb, and also excellent reliability for peak force in the left $(\mathrm{ICC}(95 \% \mathrm{CI})=0.91(0.71-0.97) ; \mathrm{TE}=13.55 \mathrm{~N}, \mathrm{CV} \%=1.61 ; \mathrm{MDC}=57.87 \mathrm{~N})$ and right $(\mathrm{ICC}(95 \% \mathrm{CI})=0.9(0.7-0.97) ; \mathrm{TE}=21.70 \mathrm{~N}, \mathrm{CV} \%=3.31 ; \mathrm{MDC}=60.11 \mathrm{~N})$ limb. This data suggests the HEL as a reliable measure of both ECC hamstring strength and inter-limb asymmetries. Practitioners should consider the HEL as a reliable choice for measuring and monitoring eccentric hamstring strength in their athletes.
\end{abstract}

Keywords: ECC hamstring strength; hamstring strain injury; hip extension lower; reliability

\section{Introduction}

Hamstring strain injury (HSI) is a very common injury in sport [1], with adverse performance [2] and financial consequences [3]. In professional soccer, HSI remains the leading cause of time lost from competition and represents $12 \%$ of all reported injuries [4]. On average, an archetypal HSI can lead to athletes missing several weeks of training or match play, with elite level soccer teams often encountering 5-6 HSI per season [5]. In a 13-year longitudinal study in men's professional soccer [6], there has been a reported 4\% annual increase in hamstring injuries. With HSI being such a problematic issue, practitioners must identify and monitor possible risk factors that may put athletes at risk of injury or recurring injury.

The current literature suggests that two main biomechanical mechanisms can lead to HSI, one resulting from high-speed running [7] and the second during stretching movements occurring at large ranges of motion [8]; both results in high-velocity ECC loading. HSI commonly arises in the late swing phase of the early stance phase of the gait cycle [9]; during this late swing, the hamstrings work eccentrically to decelerate both the thigh and 
lower leg in preparation for ground contact. However, HSI causation can be multifactorial and needs to be seen from a broader view and not just biomechanically. An early review by Opar et al. [10] proposed several modifiable and non-modifiable risk factors, including, but not restricted to, increased age, previous injury history, ethnicity, strength imbalances, flexibility, fascicle length and fatigue. Eccentric hamstring strength and inter-limb asymmetries have more recently been described as possible modifiable risk factors for HSI [11], with several studies publicizing that ECC hamstring training can reduce the incidence of HSI [12-14]. There is also a growing body of evidence [15,16] to suggest that inter-limb imbalances in hamstring strength increase the risk factor of HSI. Fousekis et al. [17] found that elite soccer players with imbalances in eccentric hamstring strength $\geq$ of $15 \%$ in the pre-season were at a greater risk ( $\mathrm{OR}=3.88 ; 95 \%$ CI 1.13 to $13.23, p=0.03)$ of HSIs. With both eccentric hamstring strength and inter-limb imbalances being identified as modifiable risk factors, the need to regularly monitor and address the identified weaknesses is essential [18].

When assessing ECC hamstring strength, isokinetic dynamometry is generally considered the gold standard measure. However, the device's high cost and its lack of portability in the field are limitations to its widespread use [19]. Recent portable devices [20,21] have allowed practitioners to monitor ECC hamstring strength and inter-limb imbalances accurately and frequently. The Nordic Hamstring Curl (NHC) is commonly used to measure ECC hamstring strength on the devices previously mentioned. Despite the success of the NHC in reducing HSI incidence [22] and the reported positive adaptions [23], protocols employing the NHC report low compliance rates in European soccer, with 83.3\% of clubs surveyed reporting poor compliance [24].

Other alternatives warrant investigation, and a viable option may be the HEL, which has the same starting position as another popular hamstring exercise, a Razor Curl. The starting point of a HEL has both the knee and the hip flexed at $90^{\circ}$, while the end position has both joints in full extension (Figure 1). The HEL has no concentric phase; it is an eccentric phase exercise only. The participant lowers themselves down during the eccentric phase resisting gravity as much as possible. When unable to control their body anymore, they drop to the floor, use their hands to help reposition themselves into the original starting position and repeat. Although the Razor Curl has the same starting position, at the end range, a concentric action is performed to return to the starting position instead of falling to the floor.

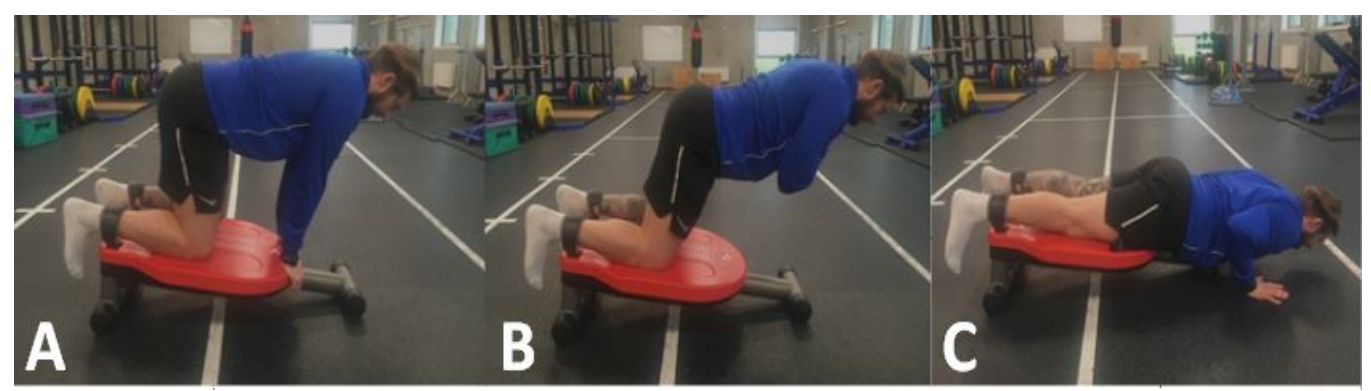

Figure 1. (A) = starting position using their hands for support until they are in a $90^{\circ}$ flexion at both knees and hips, $(\mathbf{B})=$ participant lower body in a controlled manner by contraction of the hamstrings, (C) = participant can no longer sustain the ECC hamstring contraction and land on their palms on the floor.

According to Oliver and Dougherty [25], to achieve superior activation of the hamstrings at the knee joint, there should be a stretch at the stabilized joint to work more optimally at the active joint; therefore, to maximize hamstring strength, the hips should also be flexed to $90^{\circ}$ so that a greater force may be produced at the knee joint. Previous research has investigated muscle activation [25] and architectural adaptations [26] of hamstring strengthening exercises that simultaneously involve hip and knee flexion, such as 
the HEL. However, to our knowledge, there have been no investigations into the HEL reliability as a measure of ECC hamstring strength and inter-limb asymmetries. HSI injury risk reduction should follow a multifactorial approach [27], so perhaps the assessment and monitoring of ECC hamstring strength should also be multifactorial by using exercises that have the knee in a flexed position such as the NHC and the knee and hip flexed simultaneously such as the HEL. Assessing both will provide an extensive view of the hamstring complex's uniform strength, which may help inform rehabilitation or training strategies. Oakley et al. Holistic Hamstring Health model [28], promoted the use of both hip and knee dominant exercises in hamstring training. The ability to objectively evaluate eccentric hamstring strength can help in sporting selection, post-injury prognosis, and return-to-play timeframes, as well as the assessment and identification of those at risk of injury, therefore it is important that HEL reliability is established. This current study aimed to assess the HEL reliability to measure both ECC hamstring strength and inter-limb asymmetries. It is hypothesized that the HEL will be a reliable measure for both ECC hamstring strength and inter-limb asymmetries.

\section{Materials and Methods}

\subsection{Design}

The study followed a test-retest reliability protocol. Both, average, and peak force (N) were assessed on both limbs on the Hamstring Solo device (Hamstring Solo, Kilkenny, Ireland). This device has recently been shown to be a reliable and valid measure of ECC hamstring strength and inter-limb asymmetries with the NHC. [21].

\subsection{Participants}

Twelve male professional soccer players (mean \pm SD; age: $21.8 \pm 2.9$ years; height: $180.4 \pm 5.4 \mathrm{~cm}$; mass: $75.7 \pm 6.7 \mathrm{~kg}$ ) volunteered to participate in this study. Originally 13 players were due to take part in the study, but one had to withdraw due to an injury which occurred independently of this study. Participants were from the same soccer club and covered all playing positions. Subjects were medically screened and excluded if any lower body muscle injuries had occurred six months before the intervention, or they had any current injuries. All subjects had a minimum of 2 years of resistance training experience but no experience using the Hamstring Solo device (Kilkenny, Ireland). All the participants were informed of the benefits and risks of the investigation. Participants provided informed consent, and Ethical Clearance was provided by the Institute of Technology Carlow Ethical Review Board (C00232530).

\subsection{Methods and Materials}

Participants performed two familiarization sessions to acquaint themselves with the device and exercise protocol. A minimum of $48 \mathrm{~h}$ was allowed between familiarization sessions to allow for adequate recovery. During familiarization, subjects performed a minimum of eight HEL repetitions on the Hamstring Solo device with self-selected intra-set recovery. Participants were positioned on the Hamstring Solo's cushioned surface with their ankles fixed beneath the load cells, just superior to the medial and lateral malleoli. The participant's knee position was recorded using the markings on the device, and the same knee position was used throughout the trials. Both testing sessions followed the same protocol and commenced on the same day and time over a two-week pre-season period and followed a full recovery day. Testing commenced with a dynamic warm-up that lasted approximately $12 \mathrm{~min}$. The warm-up consisted of $4 \mathrm{mins}$ of low intensity cycling, followed by 4 min dynamic stretches, targeting the gluteal, hamstrings, adductors, quadriceps, and gastrocnemius, and 4 mins of lower body exercises such as squats, lunges, and hip hinges. Participants were positioned in the device to their specific knee position; their hands were used to support them until they were in the correct position. Exact degrees of flexion were measured using a goniometer by the same researcher for each test. When in the correct position, both their knees and hips both flexed to $90^{\circ}$; they were instructed to fold 
their hands across their chest and to fully extend both their knees and hips in a controlled manner until they could no longer sustain the ECC hamstring contraction and land on their palms on the floor. They were encouraged to maintain a neutral pelvic position and limit excessive lordosis to the best of their ability. Participants were encouraged to provide maximal effort throughout each repetition. Each participant performed three repetitions with $60 \mathrm{~s}$ intra-set recovery allowed. Both average and peak force $(\mathrm{N})$ was recorded for both limbs through wireless data acquisition from the load cells and transmitted via Bluetooth to an iOS device (iPad mini).

\subsection{Statistical Analysis}

Data was expressed as mean and standard deviation. Measures of normality were assessed using the Shapiro-Wilk statistic, with normality accepted when $p>0.05$. Relative reliability was determined by calculating the Intraclass Correlation Coefficient (ICC $(2,1))$ using a Microsoft Excel Spreadsheet [29]. ICC has previously been classified as poor $(<0.40)$, fair $(0.40<0.70)$, good $(0.70<0.90)$, and excellent $(\geq 0.90)$ [30]. Typical Error (TE) and coefficient of variation $(\mathrm{CV} \%)$ were calculated to determine the magnitude of variability from the first to the second testing session [31]. CV\% was calculated as SD/Mean *100. Minimal detectable change (MDC) at a 95\% confidence level was calculated as $\mathrm{TE} \times 1.96 \times \sqrt{ } 2$.

\section{Results}

Descriptive statistics can be seen in Table 1. Test re-test's reliability measures, ICC, $\mathrm{TE}, \mathrm{CV} \%$, and MDC, can also be seen in Table 1. The HEL showed excellent reliability for average force in the left (ICC $(95 \% \mathrm{CI})=0.9(0.7-0.97)$; TE $=14.1 \mathrm{~N}, \mathrm{CV} \%=1.87$; $\mathrm{MDC}=39.06 \mathrm{~N})$ and right $(\mathrm{ICC}(95 \% \mathrm{CI})=0.91(0.73-0.97) ; \mathrm{TE}=20.89 \mathrm{~N}, \mathrm{CV} \%=3.26$; $\mathrm{MDC}=57.87 \mathrm{~N})$ limb, and also excellent reliability for peak force in the left (ICC $(95 \% \mathrm{CI})$ $=0.91(0.71-0.97) ; \mathrm{TE}=13.55 \mathrm{~N}, \mathrm{CV} \%=1.61 ; \mathrm{MDC}=57.87 \mathrm{~N})$ and right $(\mathrm{ICC}(95 \% \mathrm{CI})=0.9$ $(0.7-0.97) ; \mathrm{TE}=21.70 \mathrm{~N}, \mathrm{CV} \%=3.31 ; \mathrm{MDC}=60.11 \mathrm{~N})$ limb.

Table 1. Descriptive statistics (Mean \pm SD) and test-retest reliability data for the HEL.

\begin{tabular}{ccccccc}
\hline & Trial 1 & Trial 2 & ICC (95\% CI) & TE (N) & CV\% & MDC(N) \\
\hline Average Left (N) & $375.73 \pm 36.27$ & $381.38 \pm 41.62$ & $0.9(0.7-0.97)$ & 14.10 & 1.87 & 39.06 \\
Average Right (N) & $382.07 \pm 58.87$ & $382.20 \pm 65.10$ & $0.91(0.73-0.97)$ & 20.89 & 3.26 & 57.87 \\
Peak Left (N) & $392.99 \pm 39.18$ & $395.93 \pm 37.80$ & $0.91(0.71-0.97)$ & 13.55 & 1.61 & 37.53 \\
Peak Right (N) & $395.48 \pm 57.88$ & $394.97 \pm 63.37$ & $0.9(0.7-0.97)$ & 21.70 & 3.31 & 60.11 \\
\hline Abbreviations: ICC $=$ Intraclass Correlation Coefficient; TEM = Typical Error; MDC = Minimal Detectable Change.
\end{tabular}

\section{Discussion}

This study aimed to assess the HEL reliability to measure both ECC hamstring strength and inter-limb asymmetries. Results show the HEL has excellent reliability, and the hypothesis can be accepted that it is a reliable measure for both ECC hamstring strength and inter-limb asymmetries.

The HEL displayed excellent reliability for both left and right limbs in average force ICC 0.9 (CI, 0.7-0.97) and ICC 0.91 (CI, 0.73-0.97), respectively, peak force ICC 0.91 (CI, 0.71-0.97) and ICC 0.9 (CI, 0.7-0.97), respectively. These findings agree with similar research, which accessed the NHC on the Hamstring Solo device. The authors reported excellent reliability of left and right limbs ICC 0.91 (CI, 0.76-0.96) and ICC 0.91 (CI, 0.78-0.96), respectively, for peak force values [21]. A similar study [20] assessing the NHC but this time on a different device, the Nordboard, reported good reliability of left and right limbs ICC 0.85 (CI, 0.71, 0.93) and ICC 0.89 (CI, 0.78, 0.95), respectively, for average force, ICC $0.83(\mathrm{CI}, 0.67,0.91)$ and ICC 0.90 (CI, 0.81, 0.95), respectively, for peak force. A more recent study [32] again measuring an NHC on the Nordboard reported good to excellent reliability on both the left ICC 0.82 (CI, 0.69-0.90) and right ICC 0.82 (CI, 0.70-0.90) limbs. There is no direct comparative data for the HEL, but considering it is an eccentric hamstring exercise such as the NHC, is it fair to compare them. The HEL shows parallel results to the NHC 
regarding both average and peak force when compared to previous research [20,21,32]. These findings are valuable as they provide practitioners with another reliable option of assessing and monitoring ECC hamstring strength particularly in specific joint angles that cannot be assessed in an NHC. Reliability is important when using an exercise or device to access changes in a physical component such as ECC strength so that any changes can be attributed to the athlete's performance and not an error with the testing measure. This has importance in a clinical setting, where precision is critical to avoid misrepresenting clinical findings.

The study is not without limitations; the primary limitation was the relatively low sample size $(n=12)$. Future research should seek to include larger sample sizes. The sample population may also have been a limitation; the sample consisted of participants from the same gender, sports, and relatively similar age. A more spread population may offer a better variety of results to analyze. Another limitation was that the testing took place during pre-season, and although testing took place on the same day of each week and followed similar workloads, some residual fatigue may have negatively affected results.

Author Contributions: Conceptualization, J.O., D.B., C.L. and D.E.; resources, J.O.; writing-original draft preparation, J.O.; writing-review and editing, J.O., D.B., C.L. and D.E.; project administration, J.O. All authors have read and agreed to the published version of the manuscript.

Funding: This project was funded by the Institute of Technology Carlow, Presidents Fellowship Fund.

Institutional Review Board Statement: Institute of Technology Carlow Editorial Board (C00232530).

Informed Consent Statement: Informed consent was obtained from all subjects involved in the study.

Data Availability Statement: Data will be made available upon reasonable request to the corresponding author.

Conflicts of Interest: The authors declare no conflict of interest.

\section{References}

1. Liu, H.; Garrett, W.E.; Moorman, C.T.; Yu, B. Injury rate, mechanism, and risk factors of hamstring strain injuries in sports: A review of the literature. J. Sport Health Sci. 2012, 1, 92-101. [CrossRef]

2. Verrall, G.M.; Kalairajah, Y.; Slavotinek, J.P.; Spriggins, A.J. Assessment of player performance following return to sport after hamstring muscle strain injury. J. Sci. Med. Sport 2006, 9, 87-90. [CrossRef] [PubMed]

3. Hickey, J.; Shield, A.J.; Williams, M.D.; Opar, D.A. The financial cost of hamstring strain injuries in the Australian Football League. Br. J. Sports Med. 2014, 48, 729-730. [CrossRef]

4. Ekstrand, J.; Hägglund, M.; Waldén, M. Epidemiology of muscle injuries in professional football (soccer). Am. J. Sports Med. 2011, 39, 1226-1232. [CrossRef]

5. Ekstrand, J.; Hägglund, M.; Waldén, M. Injury incidence and injury patterns in professional football: The UEFA injury study. Br. J. Sports Med. 2011, 45, 553-558. [CrossRef] [PubMed]

6. $\quad$ Ekstrand, J.; Waldén, M.; Hägglund, M. Hamstring injuries have increased by $4 \%$ annually in men's professional football, since 2001: A 13-year longitudinal analysis of the UEFA Elite Club injury study. Br. J. Sports Med. 2016, 50, 731-737. [CrossRef]

7. Woods, C.; Hawkins, R.D.; Maltby, S.; Hulse, M.; Thomas, A.; Hodson, A. The Football Association Medical Research Programme: An audit of injuries in professional football-Analysis of hamstring injuries. Br. J. Sports Med. 2004, 38, 36-41. [CrossRef] [PubMed]

8. Askling, C.M.; Karlsson, J.; Thorstensson, A. Hamstring injury occurrence in elite soccer players after preseason strength training with eccentric overload. Scand. J. Med. Sci. Sports 2003, 13, 244-250. [CrossRef]

9. Thelen, D.G.; Chumanov, E.S.; Best, T.M.; Swanson, S.C.; Heiderscheit, B.C. Simulation of biceps femoris musculotendon mechanics during the swing phase of sprinting. Med. Sci. Sport Exerc. 2005, 37, 1931-1938. [CrossRef] [PubMed]

10. Opar, D.A.; Williams, M.D.; Shield, A.J. Hamstring strain injuries: Factors that lead to injury and re-injury. Sports Med. 2012, 42, 209-226. [CrossRef] [PubMed]

11. Opar, D.A.; Williams, M.D.; Timmins, R.G.; Hickey, J.; Duhig, S.J.; Shield, A.J. Eccentric hamstring strength and hamstring injury risk in Australian footballers. Med. Sci. Sport Exerc. 2015, 47, 857-865. [CrossRef] [PubMed]

12. Petersen, J.; Thorborg, K.; Nielsen, M.B.; Budtz-Jørgensen, E.; Hölmich, P. Preventive Effect of Eccentric Training on Acute Hamstring Injuries in Men's Soccer: A cluster-randomized controlled trial. Am. J. Sports Med. 2011, 39, 2296-2303. [CrossRef] [PubMed]

13. Hibbert, O.; Cheong, K.; Grant, A.; Beers, A.; Moizumi, T. A systematic review of the effectiveness of eccentric strength training in the prevention of hamstring muscle strains in otherwise healthy individuals. N. Am. J. Sports Phys. Ther. 2008, 3, 67-81. [PubMed] 
14. Petersen, J.; Hölmich, P. Evidence based prevention of hamstring injuries in sport. Br. J. Sports Med. 2005, 39, 319-323. [CrossRef] [PubMed]

15. Bourne, M.; Opar, D.; Williams, M.D.; Shield, A.J. Eccentric Knee Flexor Strength and Risk of Hamstring Injuries in Rugby Union. Am. J. Sports Med. 2015, 43, 2663-2670. [CrossRef] [PubMed]

16. Croisier, J.-L.; Ganteaume, S.; Binet, J.; Genty, M.; Ferret, J.-M. Strength imbalances and prevention of hamstring injury in professional soccer players. Am. J. Sports Med. 2008, 36, 1469-1475. [CrossRef] [PubMed]

17. Fousekis, K.; Tsepis, E.; Poulmedis, P.; Athanasopoulos, S.; Vagenas, G. Intrinsic risk factors of non-contact quadriceps and hamstring strains in soccer: A prospective study of 100 professional players. Br. J. Sports Med. 2011, 45, 709-714. [CrossRef] [PubMed]

18. Vicens-Bordas, J.; Esteve, E.; Fort-Vanmeerhaeghe, A.; Clausen, M.B.; Bandholm, T.; Opar, D.; Shields, A.; Thorborg, K. Eccentric hamstring strength is associated with age and duration of previous season hamstring injury in male soccer players. Int. J. Sports Phys. Ther. 2020, 15, 246-253. [CrossRef] [PubMed]

19. Buchheit, M.; Cholley, Y.; Nagel, M.; Poulos, N. The effect of body mass on eccentric knee-flexor strength assessed with an instrumented Nordic hamstring device (Nordbord) in football players. Int. J. Sports Physiol. Perform. 2016, 11, 721-726. [CrossRef] [PubMed]

20. Opar, D.A.; Piatkowski, T.; Williams, M.D.; Shield, A.J. A Novel Device Using the Nordic Hamstring Exercise to Assess Eccentric Knee Flexor Strength: A Reliability and Retrospective Injury Study. J. Orthop. Sports Phys. Ther. 2013, 43, 636-640. [CrossRef] [PubMed]

21. Lodge, C.; Tobin, D.; O'Rourke, B.; Thorborg, K. Reliability and validity of a new eccentric hamstring strength measurement device. Arch. Rehabil. Res. Clin. Transl. 2020, 2, 100034. [CrossRef] [PubMed]

22. Van Der Horst, N.; Smits, D.W.; Petersen, J.; Goedhart, E.A.; Backx, F.J. The Preventive Effect of the Nordic Hamstring Exercise on Hamstring Injuries in Amateur Soccer Players. Am. J. Sports Med. 2015, 43, 1316-1323. [CrossRef]

23. Presland, J.D.; Timmins, R.G.; Bourne, M.N.; Williams, M.D.; Opar, D.A. The effect of Nordic hamstring exercise training volume on biceps femoris long head architectural adaptation. Scand. J. Med. Sci. Sports 2018, 28, 1775-1783. [CrossRef]

24. Bahr, R.; Thorborg, K.; Ekstrand, J. Evidence-based hamstring injury prevention is not adopted by the majority of Champions League or Norwegian Premier League football teams: The Nordic Hamstring survey. Br. J. Sports Med. 2015, 49, $1466-1471$. [CrossRef]

25. Oliver, G.D.; Dougherty, C.P. The razor curl: A functional approach to hamstring training. J. Strength Cond. Res. 2009, 23, 401-405. [CrossRef]

26. Pollard, C.W.; Opar, D.A.; Williams, M.D.; Bourne, M.N.; Timmins, R.G. Razor hamstring curl and Nordic hamstring exercise architectural adaptations: Impact of exercise selection and intensity. Scand. J. Med. Sci. Sports 2019, 29, 706-715. [CrossRef]

27. Lahti, J.; Mendiguchia, J.; Ahtiainen, J.; Anula, L.; Kononen, T.; Kujala, M.; Matinlauri, A.; Peltonen, V.; Thibault, M.; Toivonen R.-M.; et al. Multifactorial individualised programme for hamstring muscle injury risk reduction in professional football: Protocol for a prospective cohort study. BMJ Open Sport Exerc. Med. 2020, 6, 758-772. [CrossRef]

28. Oakley, A.J.; Jennings, J.; Bishop, C.J. Holistic hamstring health: Not just the Nordic hamstring exercise. Br. J. Sports Med. 2018, 52, 816-817. [CrossRef]

29. Hopkins, W.G. Spreadsheets for analysis of validity and reliability. Sportscience 2015, 19, 36-42.

30. Hills, M.; Fleiss, J.L. The Design and Analysis of Clinical Experiments. J. R. Stat. Soc. Ser. A 1987, 150, 400. [CrossRef]

31. Hopkins, W.G. Measures of Reliability in Sports Medicine and Science. Sports Med. 2000, 30, 1-15. [CrossRef] [PubMed]

32. Cuthbert, M.; Comfort, P.; Ripley, N.; McMahon, J.J.; Evans, M.; Bishop, C. Unilateral vs. bilateral hamstring strength assessments: Comparing reliability and inter-limb asymmetries in female soccer players. J. Sports Sci. 2021, 39, 1481-1488. [CrossRef] [PubMed] 